\title{
Optimization of wastewater treatment plant operation for greenhouse gas mitigation
}

\author{
Dongwook Kim ${ }^{\mathrm{a}}$, James D. Bowen ${ }^{\mathrm{a} *}$, Ertunga C. Ozelkan ${ }^{\mathrm{b}}$ \\ ${ }^{a}$ UNC Charlotte, Dept. of Civil and Environmental Engineering, 9201 University City Blvd, \\ Charlotte, NC, 28223, USA \\ ${ }^{\mathrm{b}}$ UNC Charlotte, Dept. of Systems Engineering and Engineering Management, 9201 University \\ City Blvd, Charlotte, NC, 28223, USA \\ *Corresponding author: James D. Bowen, 9201 University City Blvd, Charlotte, NC, 28223, \\ USA \\ +1 704687 1215,jdbowen@uncc.edu
}

Keywords: Optimization, wastewater, greenhouse gas, modeling, performance index, sensitivity analysis

\begin{abstract}
This study deals with the determination of optimal operation of a wastewater treatment system for minimizing greenhouse gas emissions, operating costs, and pollution loads in the effluent. To do this, an integrated performance index that includes three objectives was established to assess system performance. The ASMN_G model was used to perform system optimization aimed at determining a set of operational parameters that can satisfy three different objectives. The complex nonlinear optimization problem was simulated using the Nelder-Mead Simplex optimization algorithm. A sensitivity analysis was performed to identify influential operational parameters on system performance. The results obtained from the optimization simulations for six scenarios demonstrated that there are apparent trade-offs among the three
\end{abstract} http://www.elsevier.com/open-access/userlicense/1.0/ 
conflicting objectives. The best optimized system simultaneously reduced greenhouse gas emissions by $31 \%$, reduced operating cost by $11 \%$, and improved effluent quality by $2 \%$ compared to the base case operation.

\section{Introduction}

Management of wastewater treatment plants (WWTPs) has traditionally focused on minimizing operating costs while satisfying effluent discharge limits. Effluent quality and operating costs of the plants are primarily affected by operating conditions such as solids retention time (SRT), aeration rate, and internal recycle flow rate. Optimal operation is an important part of successful management of modern wastewater treatment plants (Ostace et al., 2011; Yoon et al., 2004). In the near future, efforts must be made to extend system performance by minimizing greenhouse gas $(\mathrm{GHG})$ emissions because of the increasing attention on sustainable operation of infrastructure. Consequently, this makes the operation of WWTPs more complex and raises the possibility of trade-offs between the inherent tasks of wastewater treatment (i.e. aquatic pollutant removal at low costs) and the sustainable plant tasks (e.g. reduced global warming impact). Since all concerns may not reach their best practices simultaneously, compromises will have to be made to achieve satisfactory overall performance.

To date, the quantification of environmental and economic performance has been a major interest of system analysis in evaluating activated sludge process control strategies (Benedetti et al., 2008; Copp, 2002; Quadros et al., 2010). The main challenge in evaluating performance criteria is that quantities typically have disparate units and/or magnitudes, and thus their values may not necessarily be comparable. When system objectives can be assessed with a simple quantitative term, it is much easier for decision makers to analyze the results and find the most 
effective points of operational strategies. Therefore, an efficient approach is one that allows quantitative comparisons to evaluate management and control strategies of a plant with multiple decision criteria.

One approach to finding the best set of decisions for operating such a complex nonlinear system as wastewater treatment systems is using an optimization method with an integrated index. For wastewater treatment systems, optimal operating conditions can then be determined by means of optimization methods coupled with a predictive mathematical model of the wastewater treatment plant. A number of researchers have investigated optimization problems applied to the analysis and/or operational design of wastewater treatment plants. Most recent studies have focused either on model calibration (model parameters estimation) (Fang et al., 2009; Vanrolleghem et al., 2003; Wu and Liu, 2012) or on optimization of process design and control in different configurations (Balku and Berber, 2006; Bournazou et al., 2013; Holenda et al., 2008; Kim et al., 2000; Maere et al., 2011; Rivas et al., 2008). However, until now there are only a few studies that have attempted to tackle wastewater treatment issues by conducting optimal operations with multiple objectives using optimization algorithms. In addition, no attempt has been made to evaluate plant-wide performance by means of optimization techniques. Finally, although a lot of attention has been paid to mitigate GHG emissions in wastewater treatment plants, the evaluation of system cost and water quality performance along with GHG emissions using optimization algorithms has not been accomplished.

In this context, the objective of the work presented in this study is to employ optimization techniques to determine how the operating conditions of WWTPs could be improved: by minimizing both the operating costs and GHG emissions as well as satisfying the effluent discharge limits. For this objective, an integrated performance index is proposed that combines 
multiple criteria into a single index. Namely, quantification of the environmental impacts caused by pollutants discharges and the rate of GHG emissions are estimated and then converted into normalized scores along with operating costs. The integrated index could facilitate evaluation of system performance and comparison of the impacts of operating conditions. This work relies on a numerical model that simulates plant operation, and predicts both direct and indirect emissions of $\mathrm{CO}_{2}, \mathrm{~N}_{2} \mathrm{O}$ and $\mathrm{CH}_{4}$. The numerical model was presented and explained in detail in previous studies (Kim, 2014; Kim et al., 2015).

\section{Methods}

\subsection{Process Configuration and Operational Parameters}

The configuration of the wastewater treatment plant used in this study was a modified closed-loop Ludzack-Ettinger (MLE) process, based on the benchmark layout as presented in Nopens et al. (2010) (Fig. 1). The main process for the wastewater line comprises five bioreactors, of which the first two are anoxic and the next three are aerobic, one primary settler, and one secondary settler. Both primary and secondary sludge lines are fed to the anaerobic sludge digester. There are six operational parameters of interest in the system: (1) external carbon (i.e. methanol) dose rate into the first anoxic reactor (ECD), (2) dissolved oxygen (DO) concentration in the first aerobic reactor, (3) waste activated sludge flow rate (WS), (4) internal mixed-liquor recycle flow rate (IR), (5) return sludge flow rate (RS), and (6) operating temperature in the anaerobic sludge digester (ADT). When operated in a mode where the DO concentration was controlled by varying aeration rate, only the DO concentration in the first aerobic reactor was manipulated, and those in the following two aerobic reactors were fixed at the same concentration (i.e. $2.0 \mathrm{mg} / \mathrm{L}$ ). This is because according to the results described in Kim et al. (2015), the effects of DO concentration on GHG emissions were extremely significant in 
the first aerobic reactor due to its much more favorable environment for $\mathrm{N}_{2} \mathrm{O}$ emission by ammonia-oxidizing bacteria (AOB).

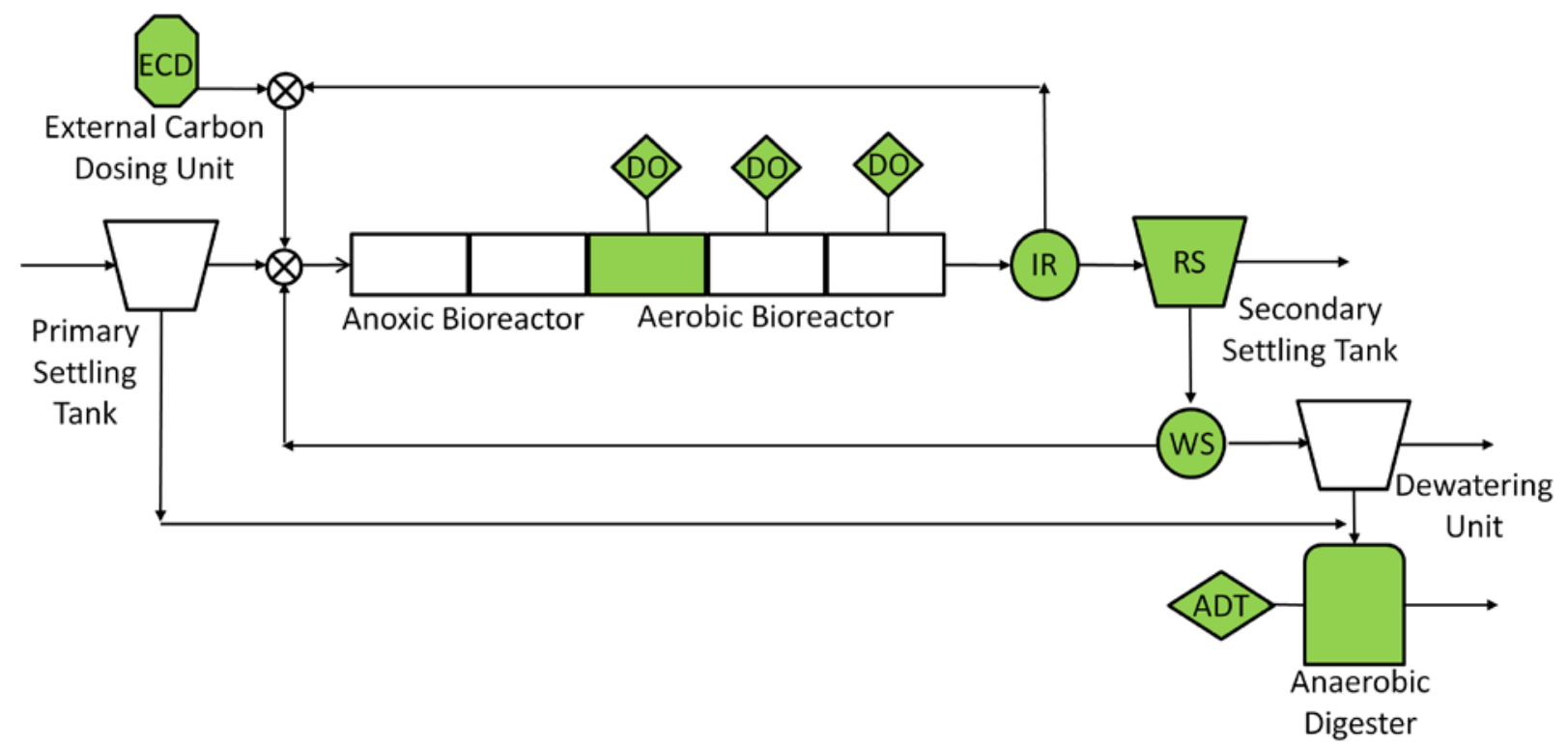

Fig. 1. Schematic diagram of the Modified Ludzack-Ettinger (MLE) process under study. The unit processes and operational parameters to be optimized are colored in green. ECD: external carbon dose rate; DO: dissolved oxygen concentration; IR: internal mixed-liquor recycle flow rate; RS: return sludge flow rate; WS: waste activated sludge flow rate; ADT: operating temperature in the anaerobic sludge digester.

\subsection{Process Models}

For a plant-wide optimization, a sludge digestion model is generally connected to an activated sludge model. In this study, the Activated Sludge Model-Nitrogen for Greenhouse gases (ASMN_G) model was employed for activated process modeling. The ASMN_G model (Kim et al., 2015) is an extension of the ASMN developed by Hiatt and Grady (2008) in order to include further knowledge on GHG emissions. The merit of the ASMN is that the model describes denitrification as a four-step process and thus $\mathrm{N}_{2} \mathrm{O}$ emissions are predictable. The 
ASMN_G model captures additional $\mathrm{N}_{2} \mathrm{O}$ emissions through the autotrophic denitrification process. It also incorporates sources and sinks of $\mathrm{CO}_{2}$ emissions by all biological processes in the model. The ADM1 model (Batstone et al., 2002) was used to simulate the sludge digestion process. This model is the most widely used model available to estimate biogas production from the sludge digestion process. The same values used in Kim (2014) were used for kinetic and stoichiometric parameters. The original coupled plant-wide GHG model needed to be modified in order to define the optimization problem (e.g. objective function, constraints, etc.) that was being analyzed.

\subsection{Performance Index}

In order to evaluate system performance when optimizing the operation of the wastewater treatment system with multi-objectives, three performance indices were introduced: Effluent Quality Index (EQI), Operational Cost Index (OCI), and Greenhouse Gas Index (GGI). These indices were intended to facilitate the evaluation of the complex non-linear problem that involves trade-offs among environmental, economic, and emissions goals. In the case of a multi-objective optimization problem, the objectives that are evaluated by different criteria of the system need to be integrated into a single quantitative measure. However, because these indices are measured in different scales or expressed in different units, they need to be appropriately combined, taking into account their complex and/or site-specific characteristics. In the context of this study, a new index named the integrated performance index (IPI) was developed. To create the IPI, the magnitude of each index was first quantified and then normalized into a dimensionless value in order to numerically combine three different types of indices. Ultimately, a weighting factor was assigned to each index, and the weighted indices were combined into a single value. These 
weighting factors allow us to specify varying site-specific preferences between the indices under different economic, environmental, and social circumstances.

Effluent Quality Index (EQI)

A composite index of effluent quality (i.e. EQI) was used to combine multiple indicators of effluent water quality. The EQI includes five major pollutants as indicators of the effluent quality: biochemical oxygen demand (BOD), chemical oxygen demand (COD), total nitrogen (TN), total Kjeldahl nitrogen (TKN), and total suspended solids (TSS). The EQI consists of two types of cost functions associated with effluent quality: the environmental costs (EC) and the violation costs (VC). First, the EC quantifies the environmental burden of effluent pollutants to a receiving water body. An example of environmental costs $\left(\mathrm{EC}_{\mathrm{BOD}}\right)$ is illustrated as:

$$
\mathrm{EC}_{\mathrm{BOD}}=\mathrm{BOD} \times \mathrm{Q}_{\mathrm{e}} \times\left[\frac{\mathrm{BOD}_{\mathrm{L}}}{10,000}+\frac{1-\frac{\mathrm{BOD}_{\mathrm{L}}}{10,000}}{1+\left(\frac{\mathrm{BOD}}{\mathrm{BOD}_{\mathrm{L}} \times 0.5}\right)^{-\mathrm{S}}}\right] \times \mathrm{W}_{\mathrm{EQL}}
$$

where $\mathrm{BOD}$ and $\mathrm{BOD}_{\mathrm{L}}$ represent the concentration of effluent $\mathrm{BOD}$ and the BOD standard limit $(\mathrm{mg} / \mathrm{L})$, respectively, $\mathrm{Q}_{\mathrm{e}}$ is the effluent flow rate $\left(\mathrm{m}^{3} / \mathrm{d}\right), \mathrm{S}$ denotes the slope of cost function, and $\mathrm{W}_{\mathrm{EQL}}$ is the weighting factor that is used for each of the five pollutants to calculate the overall effluent quality index EQI.

The environmental cost portion of the index (EC) is proportional to the amount of pollutants discharged into the environment and also proportional to a weighting factor of each pollutant. The weighting factor enables proper combining of different pollutants, and this can be determined based on the effluent limits $\left(\mathrm{EQ}_{\mathrm{j}}\right)$ by assuming that the limits would already reflect which criteria are more important in the water body. In this context, the weighting factor of each pollutant was calculated by its effluent limit divided by the effluent limit of COD, in which COD 
was used as the reference pollutant. The weighting factors for COD, BOD, TN, TKN, and TSS are 1.0, 6.0, 7.5, 20, and 1.3, respectively, and the corresponding effluent limits are 60, 10, 8.0, 3.0, and $45 \mathrm{mg} / \mathrm{L}$. The weighting factor may vary depending upon the relative importance of the pollutant to the overall water quality of the water body under study. In addition, the EC was designed to be permissive at low concentrations below background levels. In such case, there may not be any increase in the concentrations of pollutants in the receiving water body caused by the discharge. The quantification scheme was implemented by employing a logistic equation as described in the parenthesis part of Eq. (1), and its function is plotted in Fig. 2. The slope of the function allows either an increase or decrease of the magnitude of the penalty function.

Similarly, the violation cost (VC) was introduced as a constraint in order to prevent violations of the effluent limits for discharge into the environment and to force the optimization algorithm to explore only within the feasible region of the system. That is, if the concentration of any of the five criteria pollutants in the effluent exceeds its maximum permissible limit, a penalty is imposed. By assigning a large number as the violation cost, this term can serve as a constraint to limit the effluent concentrations. Finally, the overall effluent quality index was calculated as the sum of the environmental costs and the violation costs for each pollutant.

$$
E Q I=\sum_{j=1}^{5}\left(E_{j}+V C_{j}\right)
$$

where $\mathrm{EC}_{\mathrm{j}}$ and $\mathrm{VC}_{\mathrm{j}}$ are the environmental and violation costs for $\mathrm{BOD}, \mathrm{COD}, \mathrm{TN}, \mathrm{TKN}$, and TSS.

The functional form of Eq. (2) does not explicitly describe all the details of the cost function associated with effluent quality. The logic of EQI is that the $\mathrm{EC}_{\mathrm{j}}$ is applied only if effluent concentrations are below the limit (e.g., BOD $<10 \mathrm{mg} / \mathrm{L}$ ); otherwise there is a switch to 
the $\mathrm{VC}_{\mathrm{j}}$ in the function. $\mathrm{VC}_{\mathrm{j}}$ values were set to be much larger than the corresponding $\mathrm{EC}_{\mathrm{j}}$ values calculated at the concentration limit to ensure that effluent limits were not exceeded.

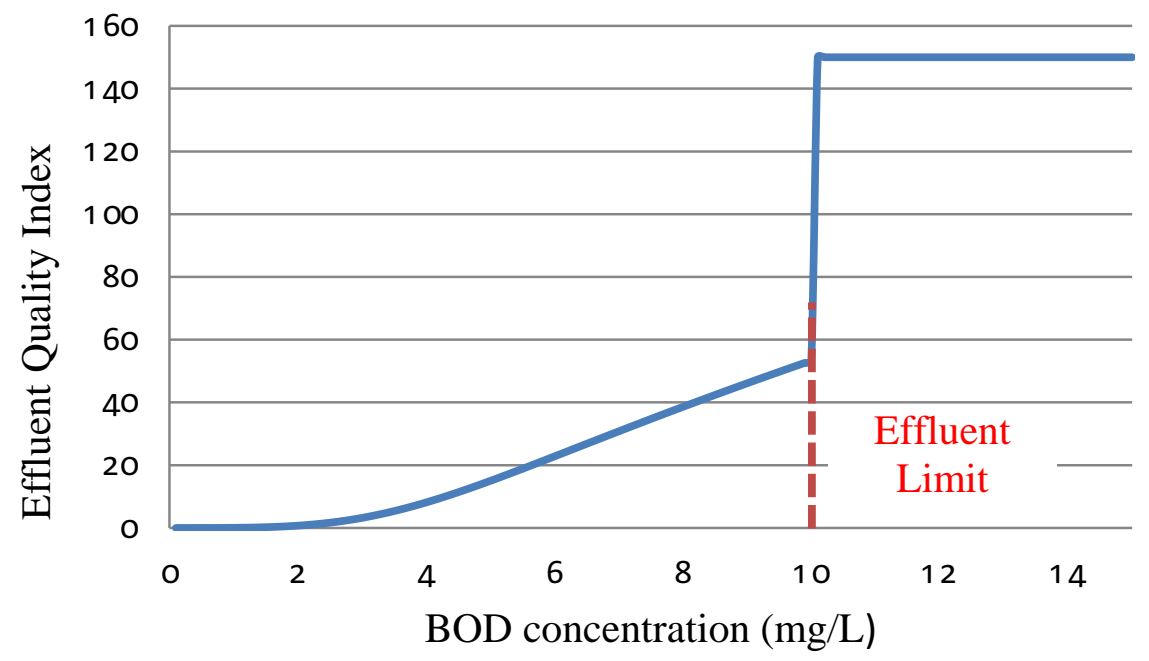

Fig. 2. Example plot of the effluent quality index of BOD effluent using Eq. (2).

\section{Operational Cost Index (OCI)}

The operating cost index (OCI) was primarily based on the approach proposed by Nopens et al. (2010). The OCI consists of major operating costs including (1) electricity use for aeration (AE), pumping (PE), mixing (ME), heating for sludge digestion (HE), and revenues from biogas energy recovery (RE), (2) external carbon dose (ECD), and (3) disposal of waste sludge produced (SP). The labor costs for maintenance and operation were not considered here. Heating energy required for digester operation was supplied by biogas collected from sludge digestion if available; otherwise electricity was used as the source of heating energy. It was assumed that excess biogas either earned revenue by being sold to other utilities or businesses, or was flared to avoid risks to human health and the environment. The operating cost index (OCI) was therefore calculated as: 


$$
\mathrm{OCI}=\left[(\mathrm{AE}+\mathrm{PE}+\mathrm{ME}+\mathrm{HE}-\mathrm{RE}) \times \mathrm{UC}_{\mathrm{EE}}+\mathrm{ECD} \times \mathrm{UC}_{\mathrm{ECD}}+\mathrm{SP} \times \mathrm{UC}_{\mathrm{SD}}\right]
$$

where UC represents the unit costs for electric energy (EE), external carbon dose (ECD), and sludge disposal (SD).

\section{Greenhouse Gas Index (GGI)}

The greenhouse gas index (GGI) took information from several sources of GHG emission from the plant, and both $\mathrm{N}_{2} \mathrm{O}$ and $\mathrm{CH}_{4}$ emissions were converted into $\mathrm{CO}_{2}$-equivalents by calculating a global warming potential (GWP). It was assumed that part of $\mathrm{CH}_{4}$ produced from the sludge digester would be captured for energy recovery or would be flared, and as a result, there would be a small fraction of uncontrollable $\mathrm{CH}_{4}$ leaks or inadvertent $\mathrm{CH}_{4}$ venting in the system. In case of $\mathrm{CH}_{4}$ capture, $\mathrm{CH}_{4}$ was converted into $\mathrm{CO}_{2}$ by a chemical $\mathrm{CO}_{2} / \mathrm{CH}_{4}$ equivalent rather than GWP and then classified as a biogenic $\mathrm{CO}_{2}$ emission. For this study, the methane capture rate was set to a default factor of $90 \%$. The greenhouse gas index (GGI) was therefore calculated as:

$$
\mathrm{GGI}=\sum_{\mathrm{i}=1}^{3}\left(\mathrm{G}_{\mathrm{i}} \times \mathrm{GWP}_{\mathrm{i}}\right)
$$

where $\mathrm{G}_{\mathrm{i}}$ is mass of $\mathrm{CO}_{2}, \mathrm{~N}_{2} \mathrm{O}$, and $\mathrm{CH}_{4}, \mathrm{GWP}_{\mathrm{i}}$ is global warming potential of $\mathrm{CO}_{2}, \mathrm{~N}_{2} \mathrm{O}$, and $\mathrm{CH}_{4}$

Integrated Performance Index (IPI)

To provide a consistent basis for the comparison of system performance, all three indices were calculated as normalized values between 0 and 1 using expected maximum and minimum values of each index as:

$$
\mathrm{x}_{\mathrm{n}}=\frac{\mathrm{x}_{\max }-\mathrm{x}}{\mathrm{x}_{\max }-\mathrm{x}_{\min }}
$$


In order to differentiate the normalized indices from the original ones shown in Eqs. (2), (3), and (4), new terms, $\mathrm{EQI}_{\mathrm{n}}, \mathrm{OCI}_{\mathrm{n}}$, and $\mathrm{GGI}_{\mathrm{n}}$ were used. Next, to integrate these three indices into a single index, weighing factors $\left(\mathrm{W}_{\mathrm{k}}, \mathrm{k}=1,2,3\right.$ such that $\mathrm{W}_{\mathrm{k}} \in[0,1]$ and $\left.\sum_{\mathrm{k}=1}^{3} \mathrm{~W}_{\mathrm{k}}=1\right)$ were assigned to each index to discriminate between more important and less important indices according to the local and site-specific preferences. The integrated performance index (IPI) was therefore defined as the weighted sum of three normalized and therefore non-dimensional criteria. As a default setting, each component in the IPI used the same weighting factor. The complete IPI was given by:

$$
\mathrm{IPI}=\mathrm{EQI}_{\mathrm{n}} \times \mathrm{W}_{\mathrm{EQI}}+\mathrm{OCI}_{\mathrm{n}} \times \mathrm{W}_{\mathrm{OCI}}+\mathrm{GGI}_{\mathrm{n}} \times \mathrm{W}_{\mathrm{GGI}}
$$

Initially, the IPI was defined as a single monetary term, but this approach was imperfect for several reasons, the most important of which was that the components were incomparable due to their different scales. Accordingly, each of the components was normalized by their range, which allowed large and small values of components to be compared.

\subsection{Definition of Optimization Problem}

The optimization problem dealt here was a multiple objective problem where trade-offs among three conflicting objectives should be made. There were three objectives to be minimized, namely (1) EQI: the amount of pollutants being discharged by the facility though effluent, (2) OCI: the operating costs, and (3) GGI: the amount of GHG emissions. These objectives conflict with one another. For example, the GHG minimization objective may adversely impact the effluent quality because pollutants present in the influent are removed in three different forms: sludge, effluent pollutants, and gases. Therefore, less carbon and nitrogen pollutions remain in the effluent if more pollutants are converted to GHGs or waste sludge. In addition, both GHG 
minimization and effluent discharge minimization objectives could be achieved at the expense of operating costs.

To define the optimization problem, let $X_{\mathrm{i}} \mathrm{i}=1, \ldots, 6$ denote the decision variables with $\mathrm{X}_{\mathrm{il}}$ and $X_{\mathrm{iu}}$ as the lower and upper bounds for each decision variable, respectively such that $X_{\mathrm{il}} \leq \mathrm{X}_{\mathrm{i}}$ $\leq \mathrm{X}_{\mathrm{u}}$. There were a total of six decision variables (operational parameters) in the optimization problem: $\left(\mathrm{X}_{1}\right)$ DO level in the first aerobic reactor, $\left(\mathrm{X}_{2}\right)$ external carbon dose rate $(\mathrm{ECD}),\left(\mathrm{X}_{3}\right)$ waste sludge flow rates (WS), $\left(\mathrm{X}_{4}\right)$ internal (nitrate) recycle flow rates (IR), $\left(\mathrm{X}_{5}\right)$ return sludge flow rates $(\mathrm{RS})$, and $\left(\mathrm{X}_{6}\right)$ operating temperature of the anaerobic digestion (ADT). These six were chosen from a larger set of operational and design parameters as the set of most likely to be significant to the objective functions (Kim et al., 2015). Initially, a sensitivity analysis was conducted in an attempt to reduce the number of decision variables further, but the analysis showed that at least one of three indices was sensitive to changes in all six of the decision variables. The control strategy was derived by means of a mathematical optimization to achieve multiple objectives simultaneously. The ranges of variation of these decision variables were established within acceptable operational conditions as shown in Table 1.

Table 1. Bounds of Decision Variables

\begin{tabular}{ccccccc}
\hline $\begin{array}{c}\text { Decision } \\
\text { variables }\end{array}$ & $\begin{array}{c}\mathrm{DO} \\
\left(\mathrm{X}_{1}\right)\end{array}$ & $\begin{array}{c}\mathrm{ECD} \\
\left(\mathrm{X}_{2}\right)\end{array}$ & $\begin{array}{c}\mathrm{WS} \\
\left(\mathrm{X}_{3}\right)\end{array}$ & $\begin{array}{c}\mathrm{IR} \\
\left(\mathrm{X}_{4}\right)\end{array}$ & $\begin{array}{c}\mathrm{RS} \\
\left(\mathrm{X}_{5}\right)\end{array}$ & $\begin{array}{c}\text { ADT } \\
\left(\mathrm{X}_{6}\right)\end{array}$ \\
\hline Unit & $\mathrm{mg} / \mathrm{L}$ & $\mathrm{m}^{3} / \mathrm{d}$ & $\mathrm{m}^{3} / \mathrm{d}$ & $\mathrm{m}^{3} / \mathrm{d}$ & $\mathrm{m}^{3} / \mathrm{d}$ & $\square \mathrm{C}$ \\
\hline $\begin{array}{c}\text { Upper bound } \\
\left(\mathrm{X}_{\text {iu }}\right)\end{array}$ & 6 & 10 & 1,200 & 150,000 & 30,000 & 40 \\
\hline $\begin{array}{c}\text { Lower bound } \\
\left(\mathrm{X}_{\mathrm{il}}\right)\end{array}$ & 1 & 0 & 300 & 30,000 & 3,000 & 30 \\
\hline
\end{tabular}


The model imposes a number of constraints on both parameters and state variables that must be satisfied. The constraints were included in the model by specifying lower and upper bounds on parameter values. In addition, five effluent constraints were specified in the objective function (i.e. in EQI) by Eq. (2) to penalize any effluent violation.

There are different methods to deal with a multi-objective optimization problem (see e.g. Goicoechea et al., 1982). The aim of these methods is to identify a non-dominated solution also referred as the "Pareto" solution. Here, we have selected a well-known technique known as the weighted-sum method, which can be considered as a specific case of the more general compromise programming technique (Zeleny, 1973). The complete optimization model is formulated as:

$$
\begin{array}{cc}
\text { Minimize IPI }= & \mathrm{EQI}_{\mathrm{n}} \times \mathrm{W}_{\mathrm{EQI}}+\mathrm{OCI}_{\mathrm{n}} \times \mathrm{W}_{\mathrm{OCI}}+\mathrm{GGI}_{\mathrm{n}} \times \mathrm{W}_{\mathrm{GGI}} \\
& \text { with } \mathrm{EQI}_{\mathrm{n}}, \mathrm{OCI}_{\mathrm{n}}, \mathrm{GGI}_{\mathrm{n}}=\mathrm{f}\left(\mathrm{X}_{\mathrm{i}}\right), \mathrm{i}=1, \ldots ., 6 \\
\text { subject to } \quad & \mathrm{X}_{\mathrm{il}} \leq \mathrm{X}_{\mathrm{i}} \leq \mathrm{X}_{\mathrm{iu}}, \mathrm{i}=1, \ldots, 6 \\
& \mathrm{EQ}_{\mathrm{j}} \leq \mathrm{EQ}_{\mathrm{j} l}, \mathrm{j}=1, \ldots ., 5 \\
& \mathrm{EQI}_{\mathrm{n}}, \mathrm{OCI}_{\mathrm{n}}, \mathrm{GGI}_{\mathrm{n}} \geq 0 \text { (see Eqs. } 2 \text { - 5) }
\end{array}
$$

where as described earlier $\mathrm{X}_{\mathrm{i}}$ is used as a short hand for the decision variables, DO, ECD, WS, IR, RS, and ADT, respectively, and $\mathrm{X}_{\mathrm{il}}$ and $\mathrm{X}_{\mathrm{iu}}$ are corresponding lower and upper bounds of each decision variable $\mathrm{X}_{\mathrm{i}}$, respectively. $\mathrm{EQ}_{\mathrm{j}}$ is used as a short hand for five constituents in the wastewater effluent (COD, BOD, TN, TKN, and TSS) with corresponding limits $\mathrm{EQ}_{\mathrm{jl}}\left(\mathrm{g} / \mathrm{m}^{3}\right)$.

\subsection{Sensitivity Analysis}

As described earlier, prior to undertaking process optimization, a sensitivity analysis was performed on the model for six operational parameters and for each objective function and the integrated objective function. The sensitivity of the performance indices and their components to 
operational parameters was implemented not only to determine the important operational parameters for plant optimization, but also to investigate the relative effects of different operational options. Based on this information, optimization could be conducted with a reduced number of parameters and the step size for solving the optimization problem could be determined. The relative sensitivity function is generally defined as the relative change in model output to the change in the model parameter. The relative sensitivity function was calculated by varying the parameters over feasible ranges and by calculating the relative percent changes in model objectives. The analysis was carried out using 80-day simulations with steady forcings. The 80-day simulation run time was determined with numerical tests as the minimum value necessary to give results that did not vary appreciably with changes in simulation time.

\subsection{Simulation Scenarios}

In order to obtain a better understanding of the behavior of the model and to find the optimal operating conditions based on the proposed performance index, six scenarios of interest were simulated and evaluated as below and briefly summarized in Table 2.

Scenario 1: A baseline optimized operational setting was established as a reference scenario at normal operational set points in order to compare with other scenarios. Both biogenic and non-biogenic emissions were included. In all scenarios, $90 \%$ of the total amount of biogas generated from the anaerobic sludge digestion process was captured and the rest was released into the environment. All the captured biogas was used for energy recovery, and the excess energy after on-site use was sold for revenue. Equal weights were assigned for each of the three objectives.

Scenario 2: There has been an ongoing debate regarding whether to include biogenic $\mathrm{CO}_{2}$ emissions in the GHG estimations or not. To test the effects of using these two alternate 
procedures for the GHG estimation, only the non-biogenic $\mathrm{CO}_{2}$ emissions generated from the bioreactor, digester, and biogas combustion were considered in this scenario.

Scenario 3: As presented in Kim et al. (2015), the final disposal of biogas in WWTPs has a major impact on both the total GHG emission estimates and the operating costs. A decision has to be made regarding the final disposal of the biogas after being captured. Therefore, in this scenario, in contrast to Scenario 1, the captured biogas was flared onsite, converting the methane to less potent $\mathrm{CO}_{2}$ rather than being used for energy recovery. Heating energy for operating the sludge digester was provided by external power supply.

Scenario 4-6: In a multi-objective optimization problem, the importance of each objective may vary depending on site-specific preferences. The proposed model expressed the importance of the individual objectives by using weighting factors. In order to more clearly evaluate the impact of respective weights of each index, in scenarios 4-6 only one index of the three was considered. In other words, for each of these scenarios 4, 5, and 6 , one index is weighted 1 and the other two indices have a value of zero. These scenarios aim at showing how the model is able to find new operational settings corresponding to varying performance preferences. The scenarios also give insight as to the potential change in the optimal value for each of the indices when the other two indexes are not considered.

Table 2. Summary of designed optimization scenarios

\begin{tabular}{|c|c|c|c|c|c|}
\hline \multirow{2}{*}{ Scenario } & \multirow{2}{*}{$\begin{array}{l}\text { Biogenic } \\
\mathrm{CO}_{2} \\
\text { included }\end{array}$} & \multirow{2}{*}{$\begin{array}{c}\text { Biogas } \\
\text { energy } \\
\text { recovery }\end{array}$} & \multicolumn{3}{|c|}{ Weighting factors } \\
\hline & & & $\mathrm{W}_{\mathrm{GGI}}$ & $\mathrm{W}_{\mathrm{OCI}}$ & $\mathrm{W}_{\mathrm{EQI}}$ \\
\hline 1 & yes & yes & $1 / 3$ & $1 / 3$ & $1 / 3$ \\
\hline 2 & no & yes & $1 / 3$ & $1 / 3$ & $1 / 3$ \\
\hline 3 & yes & no & $1 / 3$ & $1 / 3$ & $1 / 3$ \\
\hline 4 & yes & yes & 1 & 0 & 0 \\
\hline
\end{tabular}




\begin{tabular}{llllll}
5 & yes & yes & 0 & 1 & 0 \\
6 & yes & yes & 0 & 0 & 1 \\
\hline
\end{tabular}

\subsection{Optimization Methods}

In general, activated sludge processes usually have highly non-linear behavior and therefore their optimizations are prone to converge to a local optimum. As the ASMN_G model was extended from ASMN to include consideration of GHG emissions, its complexity further increased. To ensure acceptable results from optimization simulations, two strategies were implemented in this study. First, optimization simulations were performed with five different sets of starting points for operational parameters, which are randomly chosen using knowledge of the processes to be distinctly different from one another (Table 3). Although it was expected that different starting points would produce several local optima with distinctly different objective function values, it was found that the optimal objective functions were generally close to one another. Secondly, the Simplex optimization algorithm (Nelder and Mead, 1965), which is based on the sequential direct search method, was implemented to solve the six-dimensional and multiobjective optimization problem. Some applications of this method in the field of wastewater engineering can be found in the literature (Egea et al., 2007; Ludwig et al., 2011; Lust et al., 2012; Souza et al., 2008). The Simplex method was implemented using WEST simulation software (Mike by DHI, Denmark). The Simplex method is an iterative method in which iterations proceed until the algorithm converges to an optimal objective function value. Due to the complexity of the optimization problem, the iterations averaged about 300 runs and went up to a maximum of 2,000 runs before an optimal solution was obtained. 
Table 3. Starting points for optimization simulation. OCI, GGI, and EQI refer to the operational cost, greenhouse gas emission, and effluent quality components of the integrated performance index (IPI, see Eq. 6)

\begin{tabular}{|c|c|c|c|c|c|c|c|c|c|c|}
\hline \multirow{2}{*}{ No. } & \multicolumn{6}{|c|}{ Parameters } & \multirow{2}{*}{$\begin{array}{c}\text { IPI } \\
\text { (Objective) }\end{array}$} & \multirow{2}{*}{ OCI } & \multirow{2}{*}{ GGI } & \multirow{2}{*}{ EQI } \\
\hline & $\begin{array}{c}\mathrm{DO} \\
(\mathrm{mg} / \mathrm{L})\end{array}$ & $\underset{\left(\mathrm{m}^{3} / \mathrm{d}\right)}{\mathrm{IR}}$ & $\begin{array}{l}\text { WS } \\
\left(\mathrm{m}^{3} / \mathrm{d}\right)\end{array}$ & $\begin{array}{c}\text { ECD } \\
\left(\mathrm{m}^{3} / \mathrm{d}\right)\end{array}$ & $\begin{array}{c}\mathrm{RS} \\
\left(\mathrm{m}^{3} / \mathrm{d}\right)\end{array}$ & $\begin{array}{l}\text { ADT } \\
(\square \mathrm{C})\end{array}$ & & & & \\
\hline 1 & 2.0 & 86,000 & 400 & 3.5 & 23,000 & 35 & 47.262 & 15.046 & 14.365 & 17.851 \\
\hline 2 & 4.0 & 120,000 & 600 & 5 & 8,000 & 37 & 52.062 & 15.041 & 19.868 & 17.153 \\
\hline 3 & 5.0 & 140,000 & 500 & 2 & 10,000 & 33 & 43.709 & 12.273 & 14.839 & 16.598 \\
\hline 4 & 1.0 & 100,000 & 310 & 2 & 15,000 & 39 & 48.972 & 14.150 & 17.986 & 16.836 \\
\hline 5 & 3.0 & 90,000 & 800 & 1 & 12,000 & 35 & 46.501 & 9.673 & 21.277 & 15.551 \\
\hline
\end{tabular}

\section{Results}

\subsection{Sensitivity Analysis}

The sensitivity analysis determined the sensitivity of the four indices (i.e. one integrated index and three individual indices) to changes in the six operational parameters (Fig. 3). The results showed that changes in the objective function significantly altered the ranking of the relative sensitivity. Each of the indices had different significant parameters. In Fig. 3, the weight of each index was assumed to be equal. In general, insignificant parameters can be excluded for the model simulation based on the information obtained from a sensitivity analysis. However, considering the sensitivity analysis, it was decided to include all six operational parameters for the optimization simulation because they were all important to at least one of the four indices. For example, both the integrated performance and the operating costs indices were sensitive to changes in the ADT level, even though ADT has a negligible influence on both GHG emissions 
and effluent quality. In Fig. 3, the relative sensitivity functions are obtained by increasing the value of a specific parameter by $1 \%$. The relative sensitivity is calculated as the ratio of percentage change in performance index to the percentage change $(1 \%)$ in the decision variable. Positive sensitivity values would therefore produce an increase in a performance index, while negative sensitivities would produce a negative change in the performance index. In a minimization problem, such as this study, a negative change in one or more index describes a positive effect on the system performance. The sensitivity functions shown in Fig. 3 revealed that a positive sensitivity caused by one parameter could be compensated by a negative sensitivity of the other parameters.

Among the considered parameters the most significant effects on the integrated performance originated from operating temperature in the digester, while the least significant effect was found at the waste sludge flow rate. The importance of the internal (nitrate) recycle to the effluent quality is not surprising, due to the fact that the effluent nitrogen criterion is very strict and the internal recycle is the most important parameter influencing the nitrogen removal efficiency. Contrary to common knowledge on the operation of an activated sludge process, it was shown that both operating costs and effluent quality were less sensitive to DO level. This could be explained by the fact that the DO level in the first aerobic reactor is the only parameter to be optimized and the DO levels of the two other aerobic reactors are controlled at a fixed value $(2.0 \mathrm{mg} / \mathrm{L})$. Thus, this might cause a relatively small contribution to these two objectives. 

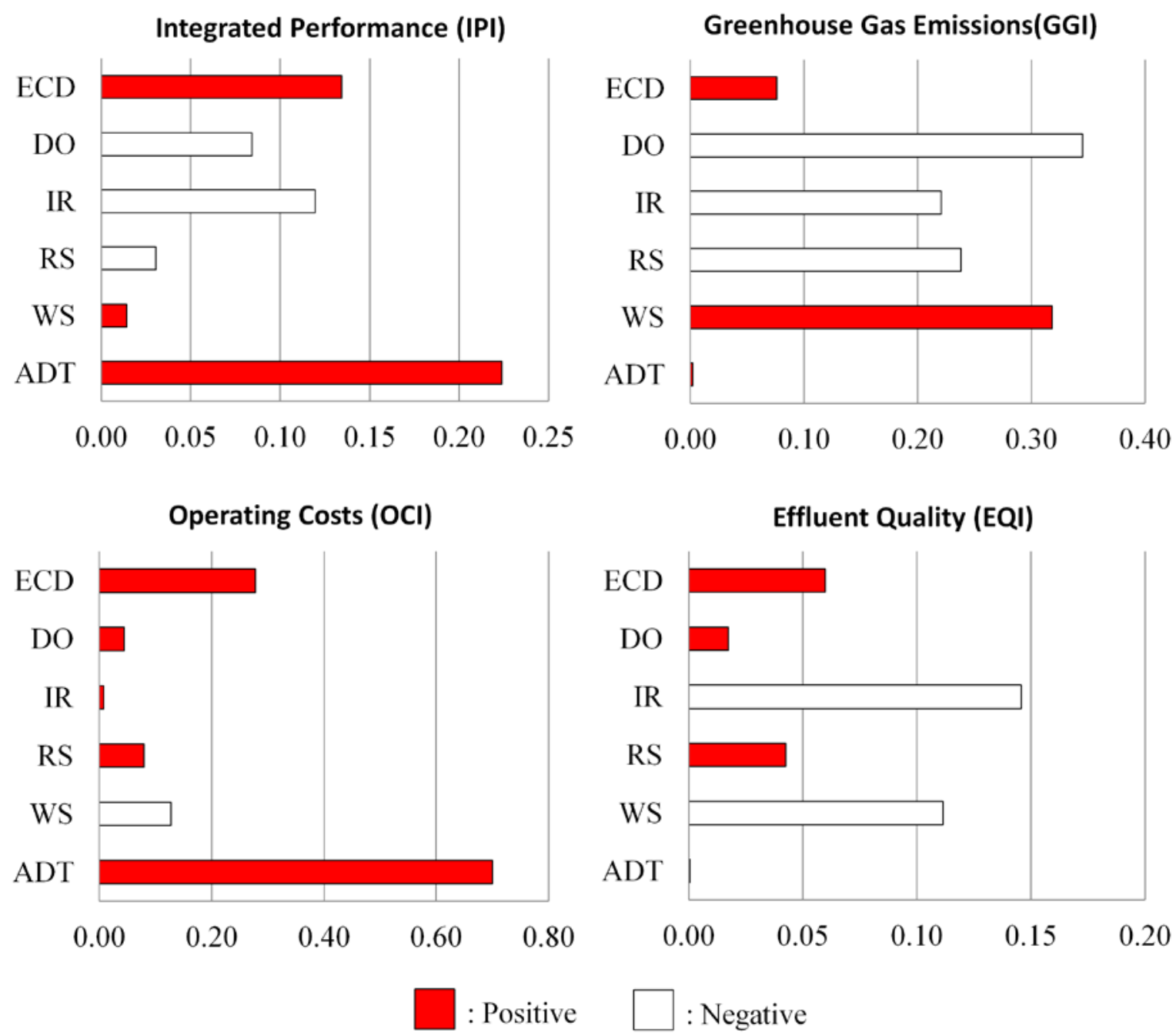

\section{Relative Sensitivity}

Fig. 3. The relative sensitivity of the four performance indices to changes in the operational parameters based upon a $1 \%$ parameter perturbation.

\subsection{Optimization of Baseline Scenario}

As has been the case in previous research on optimization of wastewater treatment processes (e.g. Fang et al., 2009; Jiang et al., 2008) in all scenarios, the optimization simulations in all scenarios converged to several local optima, due to the complexity of the model and a limitation of the search. Each starting point produced an optimal solution that had a slightly 
different vector of operating parameter values and a slightly different optimal value. For this reason, both the objective function and the optimized parameters were described by a range, which gave more information, rather than a single value. Any optimal value that was much higher than the average of the other trials was likely caused by being trapped in a local optimum for that trial and was therefore excluded from the set used to define the ranges.

The effects of the system optimization under different scenarios can clearly be seen in Figs. 4 - 5. Fig. 4 depicts improvements in overall performance that are possible through optimization of operational parameters. The magnitude of system improvements that were achieved through system optimization is expressed in terms of the integrated performance index, which tells us how much system performance is improved as a percentage of the initial level when the system is operated at the optimized operational conditions found. In Scenario 1, by performing the operation optimization, the overall system performance (IPI) was improved by approximately $15 \%$ compared to the initial performance. This value was derived from the performance improvement of the individual components of the index (i.e. the operational cost component improved $11 \%$, the greenhouse gas emission component improved $31 \%$, and the effluent quality component improved $2 \%$ ). There were clear trade-offs amongst the conflicting three objectives, although this particular result is not shown in Fig. 4. For example, the simulation results showed that decreased GHG emissions and improved effluent quality resulted in improved overall system performance (IPI), but these improvements came at the expense of increased operational costs. Fig. 5 presents a detailed description of the simulation results with non-normalized values of each index. Scenario 1 (reference case) achieved a relatively large reduction in the GHG emission index, but relatively low improvements in cost and effluent quality. 


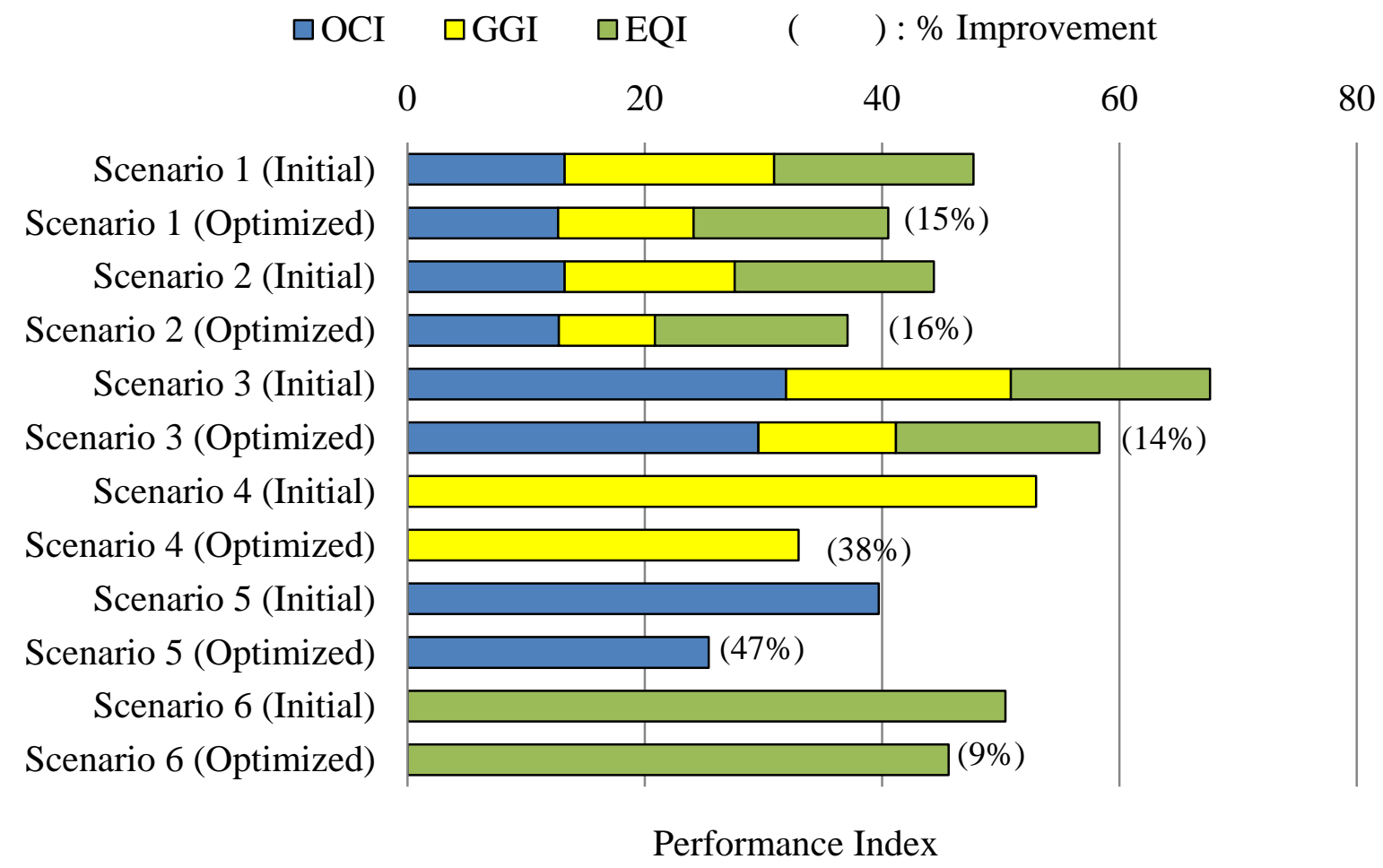

Fig. 4. Comparison of the operation cost (OCI), greenhouse gas emission (GGI) and effluent quality (EQI) components of the integrated performance index for initial and optimized conditions under six scenarios.

Some outliers were observed from the results of the optimization runs. The results of optimal operational parameters from five starting points under six scenarios are summarized in Fig. 6 after discarding the extreme outliers. Each of these bars represents a range of optimal operational parameters within a designed range (i.e. minimum and maximum values of the graph) and corresponds with its objective function value. The operational parameters converged to a limited range of optimal operational conditions. It should be noticed that the variation of more sensitive parameters such as the digester operating temperature and the methanol dose rate 
were much lower than those of other less sensitive parameters. Decision variable constraints were generally not binding except for scenario 4 , where all parameters except for external carbon dose rate were bound to a limiting value (Fig. 6).

(a)
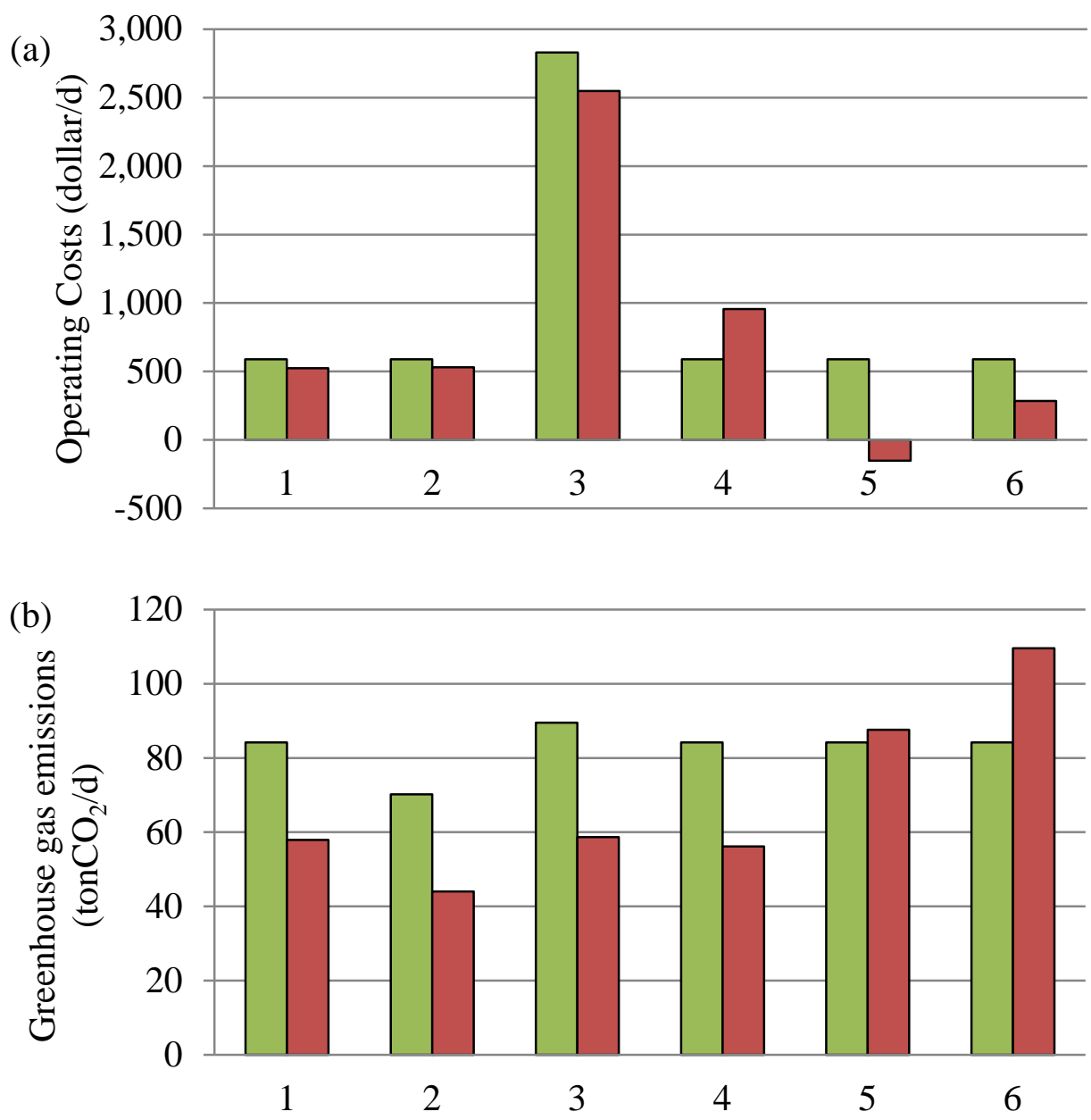
(c)

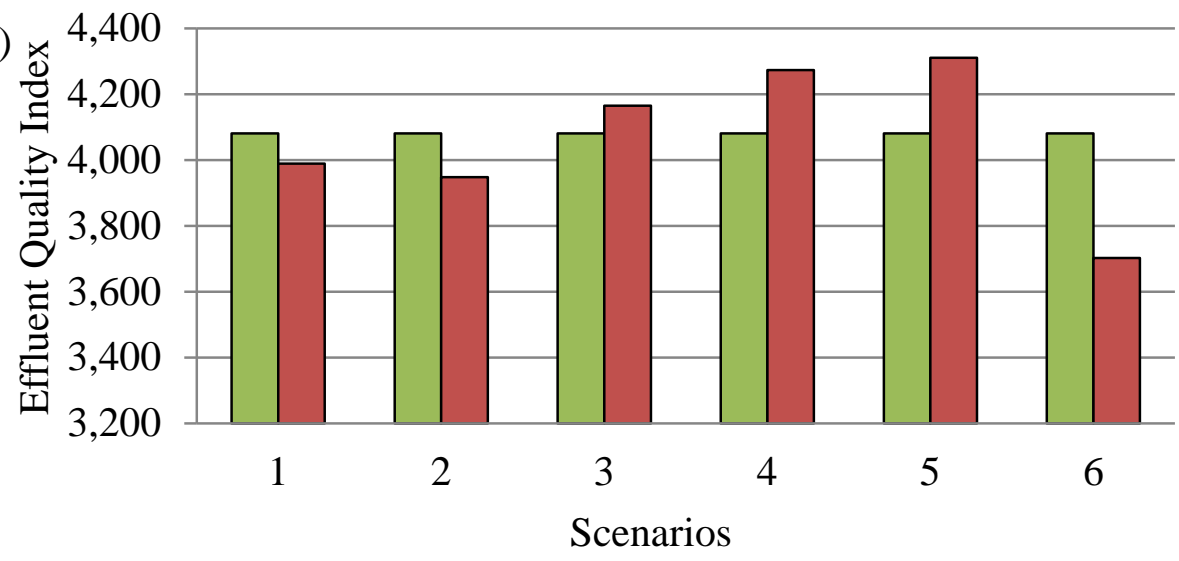

$\square$ Initial Value $\quad \square$ Optimized Value

Fig. 5. Comparison of initial and optimized values of the (a) operating costs, (b) greenhouse gas emissions, and (c) effluent quality index under six scenarios. Note that negative costs (panel (a), scenario 5) represent credit as a consequence of biogas energy recovery. 

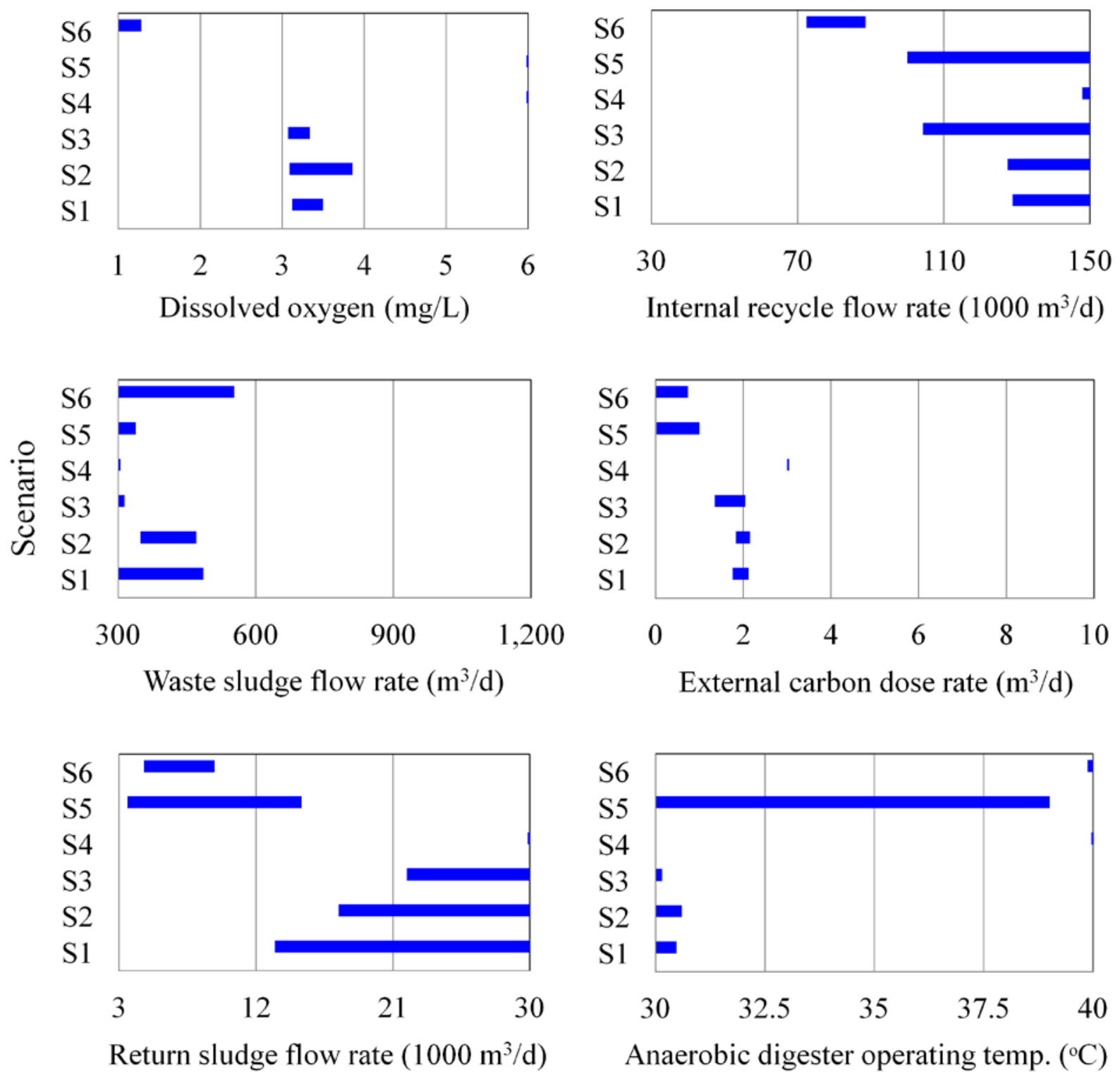

Fig.6. Range of optimized operational parameters for each scenario. The ranges of the parameters in the $\mathrm{x}$-axis show the range of optimal values for the set of starting points chosen for optimization.

\subsection{Effects of Exclusion of Biogenic $\mathrm{CO}_{2}$ Emissions}

The amount of biogenic $\mathrm{CO}_{2}$ emissions can vary depending on several factors such as influent characteristics and operational conditions. Biogenic $\mathrm{CO}_{2}$ emissions in this work 
accounted for 20 - $30 \%$ of total GHG emissions under different operational conditions or scenarios. When comparing the cases with and without biogenic $\mathrm{CO}_{2}$ emissions (Scenario 2), quite similar optimal values of operational parameters were obtained as depicted in Fig.6.

\subsection{Effects of Biogas Energy Recovery}

The biogas generated from the anaerobic digester is generally combusted for energy recovery or flared to prevent any possible hazards. There is no doubt that biogas energy recovery may be beneficial when reducing both operating costs and GHG emissions. As expected, in the

case of no energy recovery (Scenario 3), the minimum operating costs were dramatically increased by four times due to energy purchase for digester heating (Fig. 5(a)). Meanwhile, the other two objectives, GHG emissions and effluent quality, were not significantly affected in this scenario (Figs. 5 (b) and (c)), but there was an implicit trade-off among the sub-objectives. For example, the total amounts of GHG emissions were almost the same for both optima because of a trade-off between direct and indirect emissions. Energy recovery led to a slightly better effluent quality (approximately 5\% of the effluent quality component of the IPI) by allowing more carbon and nitrogen pollution present in the wastewater to be converted to gaseous pollution. Similar ranges of optimized parameters were obtained, compared to Scenario 1. However, as an exception, slightly lower ranges of waste sludge flow rate (higher solids retention time, SRT) were observed in the case of energy recovery because the waste sludge flow rate was the least sensitive parameter for both scenarios and thereby converged to a wider range of optimal values.

\subsection{Effects of Changes in Index Weights}


Based on the weight assigned to each index, the objective will be oriented towards a different optimal point. Regarding the comparison of different weights (Scenario 4 - 6), the results of optimization simulations with five different starting points showed that Scenario 4 $\left(\mathrm{W}_{\mathrm{GGI}}, \mathrm{W}_{\mathrm{OCI}}\right.$, and $\left.\mathrm{W}_{\mathrm{EQI}}=1: 0: 0\right)$ and Scenario $5\left(\mathrm{~W}_{\mathrm{GGI}}, \mathrm{W}_{\mathrm{OCI}}\right.$, and $\left.\mathrm{W}_{\mathrm{EQI}}=0: 1: 0\right)$ were significantly improved in terms of IPI (about 38 and 47\%, respectively) relative to the respective starting points (Fig. 4). This seemed to be due to high degree of flexibility in the greenhouse gas emissions and operational cost components of the integrated index. Scenario $6\left(\mathrm{~W}_{\mathrm{GGI}}, \mathrm{W}_{\mathrm{OCI}}\right.$, and $\left.\mathrm{W}_{\mathrm{EQI}}=0: 0: 1\right)$ showed the least performance improvement $(9 \%)$ of these three scenarios. The overall constraint on removal capacity of the wastewater process used is likely the main reason for this limited improvement.

The effluent quality of the plant was compared for the three scenarios. Table 4 shows that despite a weighting that considers only the environmental quality portion of the integrated index (Scenario 6, $\mathrm{W}_{\mathrm{GGI}}, \mathrm{W}_{\mathrm{OCI}}$, and $\left.\mathrm{W}_{\mathrm{EQI}}=0: 0: 1\right)$, effluent concentrations were generally not reduced. The total nitrogen (TN) concentration of Scenario 6 was actually higher than either Scenario 4 or 5. The most significant effluent improvement was accomplished for TKN. TKN concentration is the most strictly regulated under the given effluent limits. Although effluent quality was not a goal of Scenario 4 and 5, effluent quality was relatively stable throughout the simulations due to the inherent treatment capacity of the system.

Table 4. Comparison of effluent quality (mg/L) for Scenario 4 - 6

\begin{tabular}{ccccc}
\hline $\begin{array}{c}\text { EQI } \\
\text { Criteria }\end{array}$ & $\begin{array}{c}\text { Effluent } \\
\text { Limit }\end{array}$ & $\begin{array}{c}\text { Scenario 4 } \\
\left(\mathrm{W}_{\mathrm{GGI}}=1.0\right)\end{array}$ & $\begin{array}{c}\text { Scenario 5 } \\
\left(\mathrm{W}_{\mathrm{OCI}}=1.0\right)\end{array}$ & $\begin{array}{c}\text { Scenario 6 } \\
\left(\mathrm{W}_{\mathrm{EQI}}=1.0\right)\end{array}$ \\
\hline COD & 60.00 & 34.28 & 29.77 & 29.83 \\
BOD & 10.00 & 8.47 & 7.44 & 7.46 \\
TN & 8.00 & 6.60 & 6.31 & 7.12 \\
TKN & 3.00 & 2.29 & 2.98 & 2.00
\end{tabular}




\section{Discussion}

With more restrictive objectives and with the increased complexity of wastewater treatment processes, advanced operational strategies are highly demanded. Regarding the optimum operating conditions found, it seems that it would be possible to obtain very satisfactory system performance, i.e. minimizing operating costs and GHG emission, and at the same time treating the wastewater to a higher extent. Direct methane emission to the environment is thought be to be unusual at most WWTPs, and thus the contribution of methane to the total GHG emissions may be minor (less than 10\%) if it is converted to carbon dioxide. Since this is the case for methane emissions at most plants, $\mathrm{N}_{2} \mathrm{O}$ emission control is essential for the objective of minimizing GHG emissions. According to the plant-wide nitrogen balance analysis in Kim (2014), $\mathrm{N}_{2}$ and $\mathrm{N}_{2} \mathrm{O}$ are the main end gaseous products of the nitrogen removal process. Considering environmental aspects, efforts should be made to promote $\mathrm{N}_{2}$ emissions rather than $\mathrm{N}_{2} \mathrm{O}$ emissions. As seen in the results of sensitivity analysis and scenario analysis in this study, the greenhouse gas index (GGI), in particular $\mathrm{N}_{2} \mathrm{O}$ emission, is significantly affected by DO levels. In the case of equal weights of the three indices (Scenario 1-3), as seen in Fig. 6 the optimal dissolved oxygen levels in the first aerobic reactor exist between 3 and $4 \mathrm{mg} / \mathrm{L}$, at which $\mathrm{N}_{2} \mathrm{O}$ production by ammonia-oxidizing bacteria (AOB) is prevented and complete nitrification is promoted. It is therefore suggested that the DO level in the first aerobic reactor should be maintained in this range, which is $50-100 \%$ higher than the other aerobic reactors, to minimize GHG emissions. In this case, the GHG emission reduction that occurs by controlling $\mathrm{N}_{2} \mathrm{O}$ emission is much greater than the indirect emission caused by intensive aeration. 
In order to satisfy the effluent quality, it is important that the effluent TKN and TN should be properly controlled because these two water quality criteria are problematic due to their sensitivity and thereby often exceeded the effluent limits. As seen in the sensitivity analysis (Fig. 3), it is noticed that the effluent quality is significantly affected by three operational parameters: internal recycle rate, solids retention time (SRT), and external carbon (methanol) dose. A high internal recycle rate (400 - 500\% of the influent flow) is recommended for complete denitrification. In addition, a long SRT, which is controlled by the sludge waste rate, is required for nitrification, however the SRT can cause increases in effluent TKN and TN concentrations. In our simulations, the optimum sludge waste rate was between 300 and 480 $\mathrm{m}^{3} / \mathrm{d}$, corresponding to SRTs ranging from 15 to 22 days. In our simulations a methanol dose of about $2.0 \mathrm{~m}^{3} / \mathrm{d}$ was enough to allow complete denitrification. This methanol dose is approximately $40 \%$ less than the reference values.

Energy recovery from biogas is considered a worthwhile strategy because its advantage lies not only in the cost savings, but also in mitigating the environmental concerns posed by GHG emissions. The amount of biogas production is directly proportional to that of sludge production. Sludge production could be maximized by either decreased SRT or decreased biodegradation of organic substrate, resulting in an increase of organic substrate fed to the anaerobic digester. However, these strategies do not always give benefits. The well-intentioned practice of maximizing biogas production to minimize GHG emissions and operating cost may inadvertently be contributing large amounts of carbon and nitrogen loads to the environment. The denitrification process requires a carbon source, and thus external carbon would have to be added if more organic substrate is removed from the primary clarifier than is needed for the denitrification process. This can also lead to an unbalanced $\mathrm{COD} / \mathrm{N}$ ratio for the denitrification 
process, causing increased $\mathrm{N}_{2} \mathrm{O}$ production. Moreover, only the biodegradable part (i.e. volatile suspended solids) of sludge is converted to biogas, and the remaining part is transported off-site for disposal. The present model does not consider sludge transportation costs for offsite disposal, but it could give somewhat different results. A suggestion for further study here is to include these costs as well. No significant changes of the biogas production were observed within the assigned operating temperature range of the digester (30-40 $\square$ C). Biogas is often oversaturated with the digester effluent. A technology to economically recover dissolved $\mathrm{CH}_{4}$ from the effluent could make anaerobic treatment more favorable in reducing GHG emissions and operating costs.

An important issue that is often encountered when solving a nonlinear optimization problem is local optimum. In fact, as the model became more complex with the inclusion of a new model, the Simplex optimization algorithm tended to end its search at different local optima. This is a clear indication of the nonlinear nature of the system. In this study countermeasures were implemented to minimize this problem. It is important to note that the quality of optimization simulation is significantly affected by starting points of the parameters to be optimized and their step size. For a better solution, it was attempted to run the optimization simulations with different starting points. Due to the complexity of the model and the resulting substantial computational load (i.e. large amount of computational time required), only five sets of starting points of the parameters were used for each scenario. When using the WEST simulator, about 10 to 15 minutes of computational time were required per iteration in each scenario, and about two hundred to two thousand iterations were required to find an optimum solution for each scenario. Accordingly, the solution of this optimization simulation is not guaranteed to be a global optimum. Further research is therefore needed in order to reduce computational time while ensuring convergence to a proper solution. In addition, in both 
optimization algorithms, the step size of parameters was determined based on the information from regression coefficients or sensitivity analysis. From the preliminary runs by the Simplex method, it was observed that a smaller step size generally increased the number of iterations; however this did not improve the objective value for the optimal solution. An appropriate step size is crucial for obtaining correct results. Further research on these problems is needed; however it was considered beyond the scope of this study. Nevertheless, this optimization work provided a useful means for finding optimal operating conditions in WWTPs.

\section{Conclusions}

Due to increasing attention towards sustainable infrastructure, some recent studies have dealt with wastewater treatment systems by considering the reduction of GHG emissions as well as operating costs and effluent quality. However, few attempts have been made to satisfy all three objectives simultaneously. In this study, with the aid of an optimization algorithm, multiobjectives of WWTPs could be achieved simultaneously. To do this, an integrated index that combined the three objectives (low GHG emissions, low operating costs, and high effluent quality) was proposed, which was necessary for the optimization simulation and could cover all the major concerns in the wastewater treatment system. To the authors' knowledge, it was the first time that optimization simulation using activated sludge models along with these three criteria was implemented. The ASMN_G model was used to determine optimum operating conditions of the nonlinear system. From the comprehensive implementation of system optimization, it can be concluded that more sustainable systems can be achieved even in existing facilities through thoughtful selection of operational parameters. It is hoped that the proposed model could help inform decisions for evaluating the success of sustainable practices for wastewater treatment plants. In order to improve this work for practical applications, further 
research is needed to reduce the computational time and identify a proper step size used by the Simplex method.

\section{Acknowledgement}

This material is based upon work supported by the National Science Foundation under Grant No.

OCE-0813147.

\section{References}

Balku, S., Berber, R., 2006. Dynamics of an activated sludge process with nitrification and denitrification: start-up simulation and optimization using evolutionary algorithm. Comput. Chem. Eng. 30, 490-499.

Batstone, D.J., Keller, J., Angelidaki, I., Kalyuzhnyi, S.V., Pavlostathis, S.G., Rozzi, A., Sanders, W.T.M., Siegrist, H., Vavilin, V.A., 2002. Anaerobic Digestion Model No.1 (ADM1). IWA Publishing, London, UK.

Benedetti, L., Dirckx, G., Bixio, D., Thoeye, C., Vanrolleghem, P.A., 2008. Environmental and economic performance assessment of the integrated urban wastewater system. J. Environ. Manage. 88, 1262-1272.

Bournazou, M.N., Hooshiar, K., Arellano-Garcia, H., Wozny, G., Lyberatos, G., 2013. Model based optimization of the intermittent aeration profile for SBRs under partial nitrification. Water Res. 47, 3399-3410.

Copp, J.B., 2002. The COST Simulation Benchmark-Description and Simulator Manual. Office for Official Publications of the European Communities, Luxembourg.

Egea, J.A., Vries, D., Alonso, A.A., Banga, J.R., 2007. Global optimization for integrated design and control of computationally expensive process models. Ind. Eng. Chem. Res. 46, 9148-9157. Fang, F., Ni, B.J., Yu, H.Q., 2009. Estimating the kinetic parameters of activated sludge storage using weighted non-linear least-squares and accelerating genetic algorithm. Water Res. 43, 2595 2604.

Goicoechea, A., Hansen, D., Duckstein, L., 1982. Multiobjective decision analysis with engineering and business applications. John Wiley \& Sons, New York, NY.

Hiatt, W.C., Grady, C.P., Jr., 2008. An updated process model for carbon oxidation, nitrification, and denitrification. Water Environ. Res. 80, 2145-2156.

Holenda, B., Domokos, E., Redey, A., Fazakas, J., 2008. Dissolved oxygen control of the activated sludge wastewater treatment process using model predictive control. Comput. Chem. Eng. 32, 1270-1278.

Jiang, T., Myngheer, S., De Pauw, D.J., Spanjers, H., Nopens, I., Kennedy, M.D., Amy, G., Vanrolleghem, P.A., 2008. Modelling the production and degradation of soluble microbial products (SMP) in membrane bioreactors (MBR). Water Res. 42, 4955-4964. 
Kim, D., 2014. Model development and system optimization to minimize greenhouse gas emissions from wastewater treatment plants. Ph.D. dissertation. University of North Carolina at Charlotte, Charlotte, North Carolina.

Kim, D., Bowen, J.D., Kinnear, D., 2015. Comprehensive mathematical modeling of greenhouse gas emissions from water reseource recovery facilities. Water environment research : a research publication of the Water Environment Federation Accepted January 11, 2015.

Kim, H., McAvoy, T.J., Anderson, J.S., Hao, O.J., 2000. Control of an alternating aerobic-anoxic activated sludge system - Part 2: optimization using a linearized model. Control Eng. Pract. 8, 279-289.

Ludwig, T., Kern, P., Bongards, M., Wolf, C., 2011. Simulation and optimization of an experimental membrane wastewater treatment plant using computational intelligence methods. Water Sci. Technol. 63, 2255-2260.

Lust, M., Makinia, J., Stensel, H.D., 2012. A mechanistic model for fate and removal of estrogens in biological nutrient removal activated sludge systems. Water Sci. Technol. 65, 11301136.

Maere, T., Verrecht, B., Moerenhout, S., Judd, S., Nopens, I., 2011. BSM-MBR: a benchmark simulation model to compare control and operational strategies for membrane bioreactors. Water Res. 45, 2181-2190.

Nelder, J., Mead, R., 1965. A simplex method for function minimization. The Comput. J. 7, 308 $-313$.

Nopens, I., Benedetti, L., Jeppsson, U., Pons, M.N., Alex, J., Copp, J.B., Gernaey, K.V., Rosen, C., Steyer, J.P., Vanrolleghem, P.A., 2010. Benchmark Simulation Model No 2: finalisation of plant layout and default control strategy. Water Sci. Technol. 62, 1967-1974.

Ostace, G.S., Cristea, V.M., Agachi, P.Ş., 2011. Cost reduction of the wastewater treatment plant operation by MPC based on modified ASM1 with two-step nitrification/denitrification model. Comput. Chem. Eng. 35, 2469-2479.

Quadros, S., Joao Rosa, M., Alegre, H., Silva, C., 2010. A performance indicators system for urban wastewater treatment plants. Water Sci. Technol. 62, 2398-2407.

Rivas, A., Irizar, I., Ayesa, E., 2008. Model-based optimisation of wastewater treatment plants design. Environ. Modell. Softw. 23, 435-450.

Souza, S.M., Araújo, O.Q.F., Coelho, M.A.Z., 2008. Model-based optimization of a sequencing batch reactor for biological nitrogen removal. Bioresource technology 99, 3213 - 3223. Vanrolleghem, P.A., Insel, G., Petersen, B., Sin, G., De Pauw, D., Nopens, I., Weijers, S., Gernaey, K., 2003. A comprehensive model calibration procedure for activated sludge models, WEFTEC 2003, 76th Annual Technical Exhibition and Conference, Los Angeles, CA, USA. Wu, Y., Liu, S., 2012. Automating calibration, sensitivity and uncertainty analysis of complex models using the R package Flexible Modeling Environment (FME): SWAT as an example. Environ. Modell. Softw. 31, 99-109.

Yoon, S.H., Kim, H.S., Yeom, I.T., 2004. The optimum operational condition of membrane bioreactor (MBR): cost estimation of aeration and sludge treatment. Water Res. 38, 37-46. Zeleny, M., 1973. Compromise programming, in: Cochrane, J.L., Zeleny, M. (Eds.), Multiple criteria decision making. University of South Carolina Press, Columbia, SC, pp. 262- 301. 